\title{
The Influence of Support and Particle Size on the Platinum Catalysed Oxygen Reduction Reaction
}

Brian E. Hayden, Derek Pletcher, Jens-Peter Suchsland and Laura J. Williams

School of Chemistry, University of Southampton, Southampton UK SO17 1BJ. E-mail: beh@soton.ac.uk

Please cite this paper as:

Physical Chemistry Chemical Physics, 2009, 9141-9148

The publisher's version of this paper is available here: http://dx.doi.org/doi:10.1039/b910110a

\section{Related articles by Prof Brian Hayden can be found below: \\ Samuel Guerin and Brian E. Hayden, (2006) Physical Vapor Deposition Method for the High-Throughput Synthesis of Solid-State Material Libraries. J. Comb. Chem.8, 66-73 (doi:10.1021/cc050117p) \\ Samuel Guerin, Brian E. Hayden, Derek Pletcher, Michael E. Rendall, Jens-Peter Suchsland, and Laura J. Williams, (2006) Combinatorial Approach to the Study of Particle Size Effects in Electrocatalysis: Synthesis of Supported Gold Nanoparticles. J. Comb. Chem.8, 791-798 (doi:10.1021/cc060040k). \\ Samuel Guerin, Brian E. Hayden, Derek Pletcher, Michael E. Rendall, and Jens-Peter Suchsland, (2006) A Combinatorial Approach to the Study of Particle Size Effects on Supported Electrocatalysts: Oxygen Reduction on Gold. J. Comb. Chem. 8, 679- 686 (doi:10.1021/cc060041c). \\ Brian E. Hayden, Derek Pletcher, and Jens-Peter Suchsland (2007) Enhanced Activity for Electrocatalytic Oxidation of Carbon Monoxide on Titania-Supported Gold Nanoparticles. Angewandte Chemie, 46, 3530-3532 (doi:10.1002/anie.200604633) \\ Brian E. Hayden, Derek Pletcher, Michael E. Rendall, and Jens-Peter Suchsland, (2007) CO Oxidation on Gold in Acidic Environments: Particle Size and Substrate Effects. J. Phys. Chem. C 2007, 111, 17044-17051 (doi:10.1021/jp074651u). \\ Samuel Guerin, Brian E. Hayden, Christopher E. Lee, Claire Mormiche, John R. Owen, and Andrea E. Russell, (2004). Combinatorial Electrochemical Screening of Fuel Cell Electrocatalysts. J. Comb. Chem. 2004, 6, 149-158 (doi:10.1021/cc030113p).}




\title{
The Influence of Support and Particle Size on the Platinum Catalysed Oxygen Reduction Reaction
}

\author{
Brian E. Hayden*, Derek Pletcher, Jens-Peter Suchsland and Laura J. Williams \\ School of Chemistry, University of Southampton, Southampton SO17 1BJ, UK \\ beh@soton.ac.uk
}

\begin{abstract}
A range of platinum deposits, equivalent thicknesses $(\delta) 0.2-2.5 \mathrm{~nm}$ have been synthesised on carbon and reduced titania $\left(\mathrm{TiO}_{\mathrm{x}}\right)$ supports using physical vapour deposition on $(10 \mathrm{x} 10)$ arrays of electrodes. For $\delta<1.0 \mathrm{~nm}$, discrete platinum centres are formed and the $\mathrm{TiO}_{\mathrm{x}}$ supported platinum show two distinct characteristics; (a) a strong positive shift in the potential for the oxidation of monolayers of $\mathrm{CO}$ with decreasing loading of Pt leading to an inability to oxidise the $\mathrm{CO}$ on the lowest loadings and (b) a strong negative shift in the potential for the reduction of oxygen. Both observations can be understood in terms of an increase in the irreversibility of the Pt/PtO couple at such surfaces. The same trends, although significantly weaker, are seen with the carbon supported platinum, $\delta<1.0 \mathrm{~nm}$, and it is suggested that the Pt/PtO couple on carbon shows intermediate kinetics between $\mathrm{Pt}$ on $\mathrm{TiO}_{\mathrm{x}}$ and bulk Pt. These results have significant implications for understanding the mechanism of oxygen reduction on supported Pt catalysts and hence for the search for alternative supports to platinum for ORR electrocatalysts.
\end{abstract}

*Author for correspondence: Brian E. Hayden,

The School of Chemistry,

The University,

Southampton SO17 1BJ, England

Telephone: 44 (0)2380 592776

email: beh@soton.ac.uk 


\section{INTRODUCTION}

The preparation of platinum based electrocatalysts with high activity, poison tolerance and durability remains a major challenge for the commercialisation of PEM fuel cells. At present, carbon supported platinum based catalysts are universally applied in PEM fuel cell anodes and cathodes. Alternative supports for platinum have been sought for a number of reasons. For example (i) the catalytic activity of the metal can be modified by the support (ii) the durability of the catalyst may be enhanced by either reduced corrosion of the support or the stabilisation of platinum nano-particles (iii) or the catalyst support provides a more hydrophilic environment for water retention. Metal oxide supports, in particular titania, have been suggested to impart a number of these advantages as supports over carbon.

For example, $\mathrm{PtTiO}_{\mathrm{x}} \mathrm{C}$ electrocatalysts are suggested to exhibit improved water management 1,2 , and durability ${ }^{3}$ in a PEMFC without external humidification. Titania has been reported to enhance the dispersion of platinum on the membrane ${ }^{4}$ or the carbon support ${ }^{5,6}$ while Ebonex $^{\mathrm{TM}}\left(\mathrm{Ti}_{\mathrm{n}} \mathrm{O}_{2 \mathrm{n}-1}\right.$, largely $\mathrm{n}=4$ and 5$)$ has been proposed as a satisfactory support in a PEM fuel cell. ${ }^{7}$ The oxygen reduction activity in alkaline electrolyte on titania supported platinum model thin film catalysts was reported to be enhanced ${ }^{6}$ or similar to that of carbon supported platinum $^{8,9}$. The oxygen reduction activity for Pt on Ebonex ${ }^{\mathrm{TM}}$ in an acidic medium has also been reported to be high. ${ }^{10}$

We have extended the application of a high-throughput physical deposition methodology ${ }^{11}$ to produce ranges of particle sizes during the synthesis of supported metal model electrocatalysts. ${ }^{12}$ Following characterization of the particle size distributions, the activity of the supported catalysts was evaluated using silicon micro-fabricated arrays of 100 electrodes. ${ }^{13}$ Of particular interest has been the effect of the support material and the particle size on the activity of the electrocatalysts. We have so far focused our attention on supported gold particles, and indeed recently demonstrated that there is a strong substrate and particle size effect for the electrooxidation of carbon monoxide on reduced titania $\left(\mathrm{TiO}_{\mathrm{x}}\right)$ supported gold. $^{14,15}$ There also appears to be a difference in the oxygen reduction reaction (ORR) activity of gold on $\mathrm{TiO}_{\mathrm{x}}$ when compared to carbon, although an intrinsic particle size effect (independent of the support) appears to dominate the particle size dependence of the activity, with activity falling precipitously on particles of size $<2.5 \mathrm{~nm} .^{13}$

Platinum is, however, core to academic studies of electrocatalysis, and ubiquitous as an electrocatalyst in fuel cells ${ }^{16}$ and other applications of electrochemical technology. ${ }^{17}$ We have recently reported that the electrochemical surface redox behaviour of low coverages of platinum on slightly reduced titania $\left(\mathrm{TiO}_{\mathrm{x}}\right)$ model thin film catalysts is strongly influenced by the support. ${ }^{18}$ The kinetics of the platinum/platinum oxide couple are shown to change significantly with platinum loading, with the couple becoming increasingly irreversible with decreasing loading. One of the consequences of this is that the peak potential for the oxidation of the monolayer of carbon monoxide also strongly shifts positive and broadens with decreasing platinum loading. The result is that at low Pt loadings on $\mathrm{TiO}_{\mathrm{x}}, \mathrm{CO}$ cannot be oxidatively stripped from the surface of the platinum. Since the ORR activity of platinum has been closely linked to the affinity of the surface to oxygenates which can inhibit the reaction ${ }^{19}$, one may also expect a significant influence of a $\mathrm{TiO}_{\mathrm{x}}$ support on the ORR activity of platinum.

The electrocatalytic behaviour of dispersed platinum in the form of small particles supported on an inert substrate, almost universally carbon, has been extensively investigated because of 
a desire to maximise the dispersion of the expensive catalyst material. ${ }^{20,}{ }^{21}$ It has become increasingly evident, however, that the effect of particle size on the specific activity of platinum complicates the optimisation of catalyst utilisation through dispersion. A number of factors that can influence activity for structurally sensitive reactions include the agglomeration of the particles, ${ }^{22}$ and the predominant crystal faces of large $(4-10 \mathrm{~nm})$ particles. ${ }^{23}$ In the case of the oxygen reduction reaction, for example, there is an apparent decrease in the specific activity of platinum supported on carbon as the particle size decreases ${ }^{24}$ resulting in an optimum in mass activity of the catalyst at around a $3 \mathrm{~nm}$ platinum particle size. These results have been confirmed in a number of investigations using various electrolytes and a number of carbon supported platinum catalysts ${ }^{19,25-27}$ although it has also been suggested ${ }^{28,29}$ that there is no specific activity dependence on particle size, and the lower kinetics on small particles is associated with the mass transport of reactant. While the consensus is that there is indeed a particle size dependence of specific activity on carbon, it remains a debate as to whether this dependence in activity is associated with a geometric effects $^{20}$ or an increasing strength of oxygenate adsorption on smaller particles. ${ }^{19,30}$

As a continuation of our investigations of particle size and support effects in electrocatalysis using model thin film systems and high throughput techniques, we report here a comparison between the ORR activity of $\mathrm{TiO}_{\mathrm{x}}$ and carbon supported platinum. In particular we show that the $\mathrm{TiO}_{\mathrm{x}}$ support strongly hinders the ability of platinum to sustain the ORR activity, and this effect can be directly correlated with a significantly stronger influence of the $\mathrm{TiO}_{\mathrm{x}}$ support on the platinum surface reduction potential over that observed on the carbon support. The approach taken here and previously ${ }^{18}$ is to study both the ORR reaction and CO stripping on the same catalysts in order to correlate effect of the surface redox chemistry and water activation in CO oxidation, and the activity of the surface in the ORR.

\section{EXPERIMENTAL}

\subsection{Preparation of Electrodes}

The preparation of the $10 \times 10$ arrays has been described in more detail elsewhere. ${ }^{11,12}$ Screening arrays were micro-fabricated on silicon and consisted of a $10 \times 10$ array of gold pads $(1 \mathrm{~mm} \times 1 \mathrm{~mm})$ independently connected to contacts at the edge of the device $(31.8 \mathrm{~mm}$ x $31.8 \mathrm{~mm}$ ) by silicon nitride insulated gold interconnects.

The deposition of uniform $\mathrm{TiO}_{\mathrm{x}}$ substrate layers and platinum nanoparticles has been described in detail elsewhere. ${ }^{18}$ The $\mathrm{TiO}_{\mathrm{x}}$ films synthesised (ca. 60nm) are slightly substoichiometric and conducting when prepared in this way, ${ }^{12}$ and XRD indicates that they are amorphous. Carbon (ca. 60nm) was deposited using an e-gun source (graphite rods, Alfa Aesar, type 231-955-3), or externally by means of an arc carbon coating system (BOC Edwards; with carbon rods, BOC Edwards, type E085-19-030). Platinum was subsequently deposited with a graduated flux of Pt atoms across the arrays, controlled through a fixed shutter and mask in the PVD system. ${ }^{12}$ An electron evaporation source was used and the maximal evaporation rate was $1.5 \times 10^{-2} \mathrm{~nm} \mathrm{~s}^{-1}$, determined by a quartz microbalance and confirmed by deposition of thicker films and subsequent measurement with AFM and ellipsometry.

\subsection{Electrochemical Measurements}


The electrochemical measurements on the carbon or $\mathrm{TiO}_{\mathrm{x}}$ supported platinum electrode arrays were carried out simultaneously using a multi-channel current follower system described in detail elsewhere. ${ }^{25}$ Measurements were carried out at a temperature of $298 \mathrm{~K}$ in a three compartment glass cell with a water jacket. ${ }^{15}$ The cell had a Pt gauze counter electrode (Alfa Aeser 99.99\%) in a compartment separated from the working electrode compartment by a glass sinter. The reference electrode was a commercial mercury/mercuric sulphate electrode (MSE - $0.5 \mathrm{M} \mathrm{H}_{2} \mathrm{SO}_{4}$, Sentec), mounted in a Luggin capillary whose tip was placed a few millimetres from the array. All potentials presented in this paper are, however, converted to the reversible hydrogen electrode RHE ( $\mathrm{T}=298 \mathrm{~K}, 0.5 \mathrm{M} \mathrm{HClO}_{4}$,). The MSE has been calibrated before experiments against a commercial hydrogen electrode (Hydroflex, Gaskatel $\mathrm{GmbH})$ in the working electrolyte $\left(0.5 \mathrm{M} \mathrm{HClO}_{4}\right)$ and the potential was $0.697 \pm 0.010 \mathrm{~V}$.

Unless otherwise stated, cyclic voltammograms were recorded at $50 \mathrm{mV} \mathrm{s}^{-1}$. Except where otherwise stated, data were taken from the $10^{\text {th }}$ cycle although, in fact, there was little change after the first cycle (when the peaks tended to be less sharp/well defined). The use of the arrays resulted in voltammograms always being recorded at a number of electrodes with the same Pt coverage, ${ }^{18}$ demonstrating reproducibility and also allowing averaging of data and disregarding clearly spurious responses. It also allows the collection of a large number of data points, greatly enhancing the ability to define trends. Oxygen reduction has been carried out in oxygen saturated electrolyte, following the reaction with cyclic voltammetry scanning at 20 $\mathrm{mV} \mathrm{s}^{-1}$.

Experiments were carried out in perchloroic acid electrolyte $(0.5 \mathrm{M})$ prepared using ultra-pure water (ELGA Ultrapure, $18.2 \mathrm{M} \Omega \mathrm{cm}$, total organic carbon content $\leq 10 \mathrm{ppb}$ ) and concentrated perchloric acid (GFS Chemicals, double distilled). The gases used in the experiments were argon (BOC, $99.998 \%$ or Air products $99.9997 \%$ ) and CO (BOC, CP grade).

\section{RESULTS AND DISCUSSION}

\subsection{Characterisation of Pt on $\mathrm{TiO}_{x}$ and Carbon Supports}

TEM images of the reduced $\mathrm{TiO}_{\mathrm{x}}$ and carbon supported platinum surfaces with platinum equivalent thicknesses $(\delta)$ of $0.2 \mathrm{~nm}, 0.6 \mathrm{~nm}$ shown in Figure 1. For the lowest coverage of platinum, the metal is present as isolated centres of irregular shape on both substrates. The size of the platinum centres is ca. $1 \mathrm{~nm}$ on $\mathrm{TiO}_{\mathrm{x}}$ and $2 \mathrm{~nm}$ on carbon at an equivalent thickness of $0.2 \mathrm{~nm}$, with a concomitantly larger density of centres on the $\mathrm{TiO}_{\mathrm{x}}$ substrate. This suggests a higher density of nucleation sites on $\mathrm{TiO}_{\mathrm{x}}$, and a similar result was found for Au particles supported on the same substrates. ${ }^{12}$ The result is consistent with the suggestion that one of the differences between $\mathrm{TiO}_{\mathrm{x}}$ and carbon as a support for platinum is its ability to stabilise higher dispersion of the supported metal. At an equivalent thickness of $0.6 \mathrm{~nm}$, the platinum centres are beginning to agglomerate on both supports. At an equivalent thickness of $2 \mathrm{~nm}$ (not shown) almost total coverage of the support by platinum is observed; the surface appears as a complete layer with cracks. Hence, the platinum seems to grow as a two dimensional, multilayer structure on both supports, with a higher density of nucleating centres on $\mathrm{TiO}_{\mathrm{x}}$. However, this growth mode contrasts with that of gold on the reduced $\mathrm{TiO}_{\mathrm{x}}$ prepared by a similar procedure where the metal grows as hemispherical centres. ${ }^{12}$ This difference may result from a larger interaction between $\mathrm{Pt}$ and the support compared to $\mathrm{Au}$ and a concomitant decrease in mobility of Pt atoms over the support at a temperature of $300 \mathrm{~K}$, or due to the 
reduced mobility of Pt in the nucleating centre. Since the Pt centres do not have a simple geometry, the results in this paper are presented only as a function of the equivalent thickness $(\delta)$ of platinum.

The surface area of the platinum was estimated by integrating the area under the hydrogen adsorption peaks in cyclic voltammograms recorded in $0.5 \mathrm{M} \mathrm{HClO}_{4}$. The results for a number of arrays of Pt supported on $\mathrm{TiO}_{\mathrm{x}}$ and carbon are reported in Figure 2. At low $\delta$, the area of the platinum surface exposed to solution increases almost linearly with platinum loading, but at high equivalent thickness, the exposed Pt area becomes almost independent of the Pt loading. This is consistent with the TEM images of Figure 1. The dependence of the surface area on $\delta$ is, within experimental error, independent of the support. One can conclude that although the number of nucleation sites and average size of centres is different on the two supports (Figure 1), the average thickness of the platinum over-layer during growth is the same for both carbon and $\mathrm{TiO}_{\mathrm{x}}$. This interpretation of the voltammetry does assume that there is no change to the hydrogen adsorption behaviour for low platinum loadings, but throughout the work there was no evidence that the adsorption of hydrogen is particle size dependent.

\subsection{The Pt/Pt Oxide Surface Redox Couple}

Cyclic voltammograms were recorded for carbon (Figure 3A) and $\mathrm{TiO}_{\mathrm{x}}$ (Figure 3B) supported platinum electrodes with various equivalent thicknesses $(\delta)$ of platinum in $0.5 \mathrm{M} \mathrm{HClO}_{4}$. The voltammograms are presented as current density based on the geometric area of the electrode pads in the array. It can be seen that the voltammograms always have the general features normally associated with the surface oxidation and reduction of platinum even if the hydrogen adsorption/desorption peaks are less sharp than observed with clean, bulk platinum. ${ }^{31}$ There are no features in the cyclic voltammograms resulting from the electrochemistry of the as deposited carbon or $\mathrm{TiO}_{\mathrm{x}}$ substrate (in the absence of platinum) in this potential range, in agreement with the literature. ${ }^{32}, 33$ While for $\delta>1.0 \mathrm{~nm}$ of platinum (not shown) the voltammograms are similar to bulk Pt for both $\mathrm{TiO}_{\mathrm{x}}{ }^{18}$ and carbon supported layers significant changes can be noted for lower loadings.

For $\delta<1.0 \mathrm{~nm}$ of Pt on carbon (Figure 3A) there are still many similarities to bulk platinum. There is, however, a clear trend for the potential for reduction of the PtO to shift negative with decreasing Pt loading, moving from $+0.78 \mathrm{~V}_{\mathrm{RHE}}$ for thicker layers to $0.64 \mathrm{~V}_{\mathrm{RHE}}$ at $\delta=$ $0.21 \mathrm{~nm}$. On the other hand, there is no significant change to the shape or potential of the wave for the formation of PtO and the charges associated with both the formation and reduction of the PtO are proportional to the decrease in the hydrogen adsorption charge, ie. $\mathrm{Pt}$ surface area. Figure 4 reports data for the reduction peak normalised for surface area as a function of Pt loading.

In comparison, the voltammograms for the surfaces with $\delta<1.0 \mathrm{~nm}$ of Pt on $\mathrm{TiO}_{\mathrm{x}}$ (Figure 3B) show more marked changes. The most obvious change with decreased Pt loading is a marked decrease in charge for the formation of surface oxide without a comparable change to the charge for the adsorption of hydrogen. This apparent decrease in the extent of surface oxidation is confirmed by plotting the charge for the reduction of the PtO normalised for the surface area of Pt versus Pt thickness, see figure 4. With the $\mathrm{TiO}_{\mathrm{x}}$ substrate the extent of surface oxidation is dropping off steeply below $\delta=0.5 \mathrm{~nm}$. The potential of the peak for the reduction of PtO again shifts negative with decreasing Pt loading and, indeed, the shift is larger than for the Pt on carbon; the peak potential is $0.58 \mathrm{~V}_{\mathrm{RHE}}$ at $\delta=0.21 \mathrm{~nm}$. 
The behaviour of the $\mathrm{Pt}$ on the $\mathrm{TiO}_{\mathrm{x}}$ support has been reported previously and it was interpreted in terms of an increasing irreversibility of the surface redox behaviour with decreasing loading on this support. ${ }^{18}$ Certainly, the oxide is becoming more difficult to form with the smaller centres. The results for Pt on carbon are less conclusive. The peak for the reduction of the oxide, shows the negative shift in peak potential with decreasing Pt loading that would be associate with increasing irreversibility but the oxidation wave does not show the corresponding changes. In the literature, the negative shift in the reduction peak potential has been interpreted as evidence that the $\mathrm{Pt}-\mathrm{O}$ bond become stronger with smaller $\mathrm{Pt}$ centres. ${ }^{19,} 30$ The negative shift in the wave for the formation of PtO, consistent with this interpretation has never been observed. In fact, Maillard et al ${ }^{34}$ report a small positive shift. In consequence, we would propose that the behaviour of the $\mathrm{Pt} / \mathrm{PtO}$ couple should be interpreted as resulting from a decrease in the kinetics of the $\mathrm{Pt} / \mathrm{PtO}$ couple with decreasing $\mathrm{Pt}$ centre size with small Pt centres on $\mathrm{C}$ showing intermediate behaviour between thick layers of Pt on either substrate and Pt on $\mathrm{TiO}_{\mathrm{x}}$.

\subsection{Carbon Monoxide Stripping}

$\mathrm{CO}$ stripping voltammetry was carried out on the arrays of carbon (Figure 5A) and $\mathrm{TiO}_{\mathrm{x}}$ (Figure 5B) supported platinum catalysts. The arrays of electrodes were immersed in $\mathrm{CO}$ saturated $0.5 \mathrm{M} \mathrm{HClO}_{4}$ for a period of 15 minutes. The electrolyte was then changed to $\mathrm{Ar}$ saturated $0.5 \mathrm{M} \mathrm{HClO}_{4}$ when cyclic voltammograms were recorded at $50 \mathrm{mV} \mathrm{s}{ }^{-1}$. Results are shown for $0.21<\delta \mathrm{nm}<1.85$ for platinum on the two supports: The currents on the second cycle have been subtracted from the first cycle.

At $\delta=1.85 \mathrm{~nm}$ on both substrates, the voltammograms are similar to those at bulk Pt with single sharp oxidation peaks; the peak potentials are also similar $\left(0.74 \mathrm{~V}_{\mathrm{RHE}}\right.$ and $0.70 \mathrm{~V}_{\mathrm{RHE}}$ for $\mathrm{TiO}_{\mathrm{x}}$ and carbon supports respectively). Strong differences between the two substrates are, however, seen as the Pt loading is reduced. With the Pt on carbon surfaces, there is a trend to broader oxidation peaks at more positive potentials with decreased Pt loading but the charge associated with oxidation of CO remains constant even for $\delta=0.21 \mathrm{~nm}$ and the charge is consistent with $2 \mathrm{e}^{-}$oxidation of the $\mathrm{CO}$ of a complete monolayer (see figure 6). These observations are consistent with an earlier paper. ${ }^{18}$ With the Pt on $\mathrm{TiO}_{\mathrm{x}}$ support, the peak broadening and the positive shift in the peak potential with decreased loading is more pronounced. In addition, when $\delta<0.8 \mathrm{~nm}$, the charge associated with the $\mathrm{CO}$ oxidation peak is found to decrease and for $<0.5 \mathrm{~nm}$, no stripping peak is seen negative to the positive limit for the voltammetry $\left(+1.20 \mathrm{~V}_{\mathrm{RHE}}\right.$ ). The absence of hydrogen adsorption/desorption peaks at more negative potentials demonstrates that the $\mathrm{CO}$ is adsorbed but not oxidised. Figure 6, a plot of the ratio of charge under the CO stripping peak to the charge under the hydrogen UPD peak, emphasises the difference in $\mathrm{CO}$ stripping between the carbon and $\mathrm{TiO}_{\mathrm{x}}$ supports. Note that the error associated with each point is ca. $+/-25 \%$. While the decrease in the ratio for Pt on $\mathrm{TiOx}$ at low equivalent thicknesses is unambiguous, the apparent rise in the ratio for $\mathrm{Pt}$ on carbon is more ambiguous, and we would have no explanation for such an effect.

The literature on the oxidation of CO monolayers on platinum is very extensive and there is universal agreement that the key step is the reaction of an oxidised Pt surface atom with an adjacent adsorbed $\mathrm{CO}$ molecule

$$
\mathrm{Pt}-\mathrm{CO}+\mathrm{Pt}-\mathrm{OH} \longrightarrow 2 \mathrm{Pt}+\mathrm{CO}_{2}
$$


with the initial formation of the oxidised Pt species being difficult within a complete monolayer of CO. Once free Pt surface sites become formed, the oxidation becomes relatively facile and the oxidation of the monolayer goes to completion. Hence, the behaviour of the small Pt centres on carbon is consistent with this mechanism if it is postulated that it becomes more difficult to form the initial oxidised Pt sites with decreasing Pt centre size but this is always possible with a sufficient overpotential. With the Pt on $\mathrm{TiO}_{\mathrm{x}}$ surfaces it is likewise more difficult to form the initial oxidised Pt surface sites with decreased Pt centre size and below a critical size of Pt centre, it becomes impossible to create them and the monolayer of $\mathrm{CO}$ remains un-oxidised. Because the surfaces produced by physical vapour deposition have a distribution of $\mathrm{Pt}$ centre sizes, the change from complete monolayer oxidation to no stripping occurs over a narrow range of equivalent Pt thickness.

Overall, the results are totally consistent with the concept that it becomes more difficult to oxidise the Pt surface with decreasing Pt centre size and that this trend is much stronger on the $\mathrm{TiO}_{\mathrm{x}}$ substrate than the carbon substrate. We have no evidence that the differences we are observing are associated with the particle morphology, since the TEM show similar structures on both carbon and $\mathrm{TiO}_{\mathrm{x}}$ supports. It should also be noted that these electrochemical effects are much more prominent than the perturbations in $\mathrm{CO}$ oxidation kinetics that arise either from the agglomeration of the particles, ${ }^{22}$ or the crystal face effects observed on large (4$10 \mathrm{~nm})$ particles. ${ }^{23}$ In addition, the effects described here take place at equivalent thicknesses of Pt where agglomeration is not taking place, and the size of the Pt centres are 1-4nm.

\subsection{The Oxygen Reduction Reaction}

Figure 7 shows the results for the currents associated with the oxygen reduction reaction (ORR) reaction measured in the positive going scan of cyclic voltammetry measurements at $20 \mathrm{mVs}^{-1}$. Measurements have been made on the arrays of both carbon (Figure 7A) and $\mathrm{TiO}_{\mathrm{x}}$ (Figure 7B) supported platinum in oxygen saturated solution at $25^{\circ} \mathrm{C}$. With both substrates, a limiting current is observed at the higher overpotentials and this results from mass transport control. At low overpotentials where the currents are much less than the limiting value, the currents are significantly influenced by the nature of the surface. In the case of both carbon and $\mathrm{TiO}_{\mathrm{x}}$ supported $\mathrm{Pt}$, the overpotential for oxygen reduction is increased for $\delta<1 \mathrm{~nm}$, in the region where isolated platinum centres are formed. When comparing this decrease in activity (increase in overpotential) on carbon (Figure 7A) and $\mathrm{TiO}_{\mathrm{x}}$ (Figure 7B) supported platinum, however, it is apparent that the effect is significantly larger in the case of the titania support over the same ranges of $\delta$. The $\mathrm{TiO}_{\mathrm{x}}$ supported Pt appears unable to support strong catalysis of the ORR as soon as discrete centres are formed.

We have compared, for both carbon and $\mathrm{TiO}_{\mathrm{x}}$ supported platinum, the surface reduction peak potential, $E_{S R}$, and the ORR activity. The latter is represented by $E_{O R R}$, the potential at which the ORR specific current density (established using the platinum area determined by $\mathrm{H}_{\mathrm{ads}}$ ) is $0.01 \mathrm{~mA} \mathrm{~cm}^{-2}$ (a current which is sufficiently small to be dominated by the surface kinetics). Both $E_{O R R}$ and $E_{S R}$ are plotted as a function of $\delta$ for the carbon (Figure 8A) and TiOx (Figure 8B) supported platinum electrodes. In the case of both supports, there is a clear decrease in the ORR activity, as measured by the decreasing $E_{\mathrm{ORR}}$, and the platinum surface reduction potential $\mathrm{E}_{\mathrm{SR}}$, and this effect is largest once the discrete platinum centres are formed at $\delta<1.0$ $\mathrm{nm}$. One should note, however, that the effects on the $\mathrm{TiO}_{\mathrm{x}}$ supported platinum are significantly larger than on the carbon support (the ordinates scale for both $E_{\mathrm{ORR}}$ and $\mathrm{E}_{\mathrm{SR}}$ 
differs on Figure $8 \mathrm{~A}$ and $8 \mathrm{~B}) . \mathrm{E}_{\mathrm{ORR}}$ is in the range $0.77-0.87 \mathrm{~V}_{\mathrm{RHE}}$ for $\mathrm{Pt}$ on the carbon support for $\delta<0.6 \mathrm{~nm}$ (platinum centre sizes between 2nm to the onset of agglomeration), while $\mathrm{E}_{\mathrm{ORR}}$ is $0.45 \mathrm{~V}_{\mathrm{RHE}}$ for $\mathrm{Pt}$ on the $\mathrm{TiO}_{\mathrm{x}}$ support for $\delta<0.6 \mathrm{~nm}$ (platinum centre sizes between $1 \mathrm{~nm}$ to the onset of agglomeration). Pt centres of, say $2 \mathrm{~nm}$, clearly have significantly different relativities on carbon and on $\mathrm{TiO}_{\mathrm{x}}$.

As pointed out, the decrease in $\mathrm{E}_{\mathrm{SR}}$ on carbon supported Pt is consistent with the observations on carbon supported platinum catalysts. ${ }^{25}$ One is tempted to conclude that the even more prominent reduction in ORR activity is greater on $\mathrm{TiO}_{\mathrm{x}}$ supported platinum primarily because the surface reduction peak potential is shifted even further than an the carbon support as $\delta$ is reduced. One may expect, if this correlation between $E_{O R R}$ and $E_{S R}$ were universal between supports, that their dependence would lie on a common line. This is, however, far from the case. Figure 9 is a plot showing the relationship between $E_{O R R}$ and $E_{S R}$ on the carbon (filled circles) and $\mathrm{TiO}_{\mathrm{x}}$ (open circles) platinum electrodes over the range of $\delta$ prepared in this study. There is a steady, but relatively small, decrease in $E_{\mathrm{ORR}}$ as $\mathrm{E}_{\mathrm{SR}}$ decreases. For the $\mathrm{TiO}_{\mathrm{x}}$ support, the relationship between $\mathrm{E}_{\mathrm{ORR}}$ and $\mathrm{E}_{\mathrm{SR}}$ lies on the same curve, but only for a small range of values where $\delta>1 \mathrm{~nm}$, i.e., where the platinum covers the support. As soon as isolated centres are formed on the $\mathrm{TiO}_{\mathrm{x}}$ supported platinum electrodes $\delta<1 \mathrm{~nm}$, there is a precipitous decrease in the $\mathrm{E}_{\mathrm{ORR}}$ with decreasing $\mathrm{E}_{\mathrm{SR}}$. The decrease in activity on the carbon support is very much less over the same range of surface reduction potential shift $\left(0.78 \mathrm{~V}_{\mathrm{RHE}}\right.$ $\left.0.7 \mathrm{~V}_{\mathrm{RHE}}\right)$. We must conclude that there is no simple relationship between the surface reduction potential (and hence the apparent strength of the oxygenate bond) and the ORR activity with particle size, and that there is a much stronger influence of particle size on the ORR activity of the platinum on the $\mathrm{TiO}_{\mathrm{x}}$.

For the carbon supported platinum, it has been pointed out earlier ${ }^{19,} 30$ that there is an apparent correlation of the decreasing activity for the ORR and the shift in PtO reduction potential as the Pt loading is decreased. These authors explained this observation through the blocking of the ORR by adsorbed oxygenate. It was suggested that the smaller particles bind oxygen more strongly, which causes the shift in surface reduction peak potential and reduces the ORR rate. It should be recognised that this is not a unique explanation. The same trend would be observed if the kinetics of the Pt/PtO couple declined with Pt centre size and the ORR involved the cleavage of the O-O bond with the formation of Pt-O bonds; slower kinetics in the formation of the Pt-O bond would again have an adverse effect on the catalysis.

\section{CONCLUSIONS}

Model carbon and $\mathrm{TiO}_{\mathrm{x}}$ supported $\mathrm{Pt}$ catalysts have been successfully synthesised and characterised using physical vapour deposition using gradient techniques which allow control of the effective coverage $(\delta)$, and hence the range of Pt centre sizes on a single masked 10x10 array of micro-fabricated electrodes.

For equivalent thicknesses of platinum, $\delta>1.0 \mathrm{~nm}$, the substrates become fully covered by metal and the voltammetric responses are very similar to bulk platinum for all reactions. For $\delta$ $<1.0 \mathrm{~nm}$, discrete platinum centres are formed at both carbon and reduced titania surfaces. At such surfaces, it is found that the voltammetric responses for (a) the formation/reduction of surface platinum oxide (b) the oxidation of $\mathrm{CO}$ monolayers on $\mathrm{Pt}$ and (c) the reduction of oxygen are all influenced by the Pt loading, the effects being stronger at the $\mathrm{TiO}_{\mathrm{x}}$ substrate 
than the carbon substrate. All these results can be understood if the kinetics of the Pt/PtO couple decrease with decrease in the Pt centre size and this effect is stronger at $\mathrm{TiO}_{\mathrm{x}}$ than the carbon substrate.

There results have significant implications for understanding the mechanism of oxygen reduction on supported Pt catalysts and hence for the search for alternative supports to platinum for ORR electrocatalysts. Since the kinetics of the surface redox process is shown to be strongly influenced by both particle size and support, the platinum surfaces oxidising at high overpotential are also likely to be less effective in activating oxygen for subsequent reduction. In the case of titania, which has been suggested in the literature to provide a stable alternative support to carbon, the irreversibility in the surface redox process is significant for highly dispersed platinum, and the ORR is very inefficient The results suggest a strong support effect in the case of titania, and that while large particles supported on titania may be effective in ORR, dispersion of Pt on titania will be highly disadvantageous as a result of the strong concomitant decrease in the specific ORR activity.

We do not wish at this stage to speculate as to the origin of this effect, although an understanding of it will be essential in the selection of alternative supports to carbon for platinum particles. One may expect that the stronger interaction of Pt on titania will lead to a change in the oxophilicity of the platinum centre. However, it should be stressed that, unlike the gas phase, the kinetics of the surface redox couple (and hence oxygen activation in oxygen reduction) will be influenced by the adsorption of both water and anion (here, perchlorate). 


\section{REFERENCES}

1 M. Watanabe, H. Uchida, Y. Seki, M. Emori and P. Stonehart, Journal of the Electrochemical Society, 1996, 143, 3847-3852.

2 H. Uchida, Y. Ueno, H. Hagihara and M. Watanabe, Journal of the Electrochemical Society, 2003, 150, A57-A62.

3 J. Tian, G. Q. Sun, M. Cai, Q. Mao and Q. Xin, Journal of the Electrochemical Society, 2008, 155, B187-B193.

4 M. Gustavsson, H. Ekstrom, R. Hanarp, L. Eurenius, G. Lindbergh, E. Olsson and B. Kasemo, Journal of Power Sources, 2007, 163, 671-678.

5 Y. K. Choi, S. S. Seo, K. H. Chjo, Q. W. Choi and S. M. Park, Journal of the Electrochemical Society, 1992, 139, 1803-1807.

6 J. M. Chen, L. S. Sarma, C. H. Chen, M. Y. Cheng, S. C. Shih, G. R. Wang, D. G. Liu, J. F. Lee, M. T. Tang and B. J. Hwang, 3rd International Conference on Materials for Advanced Technologies (ICMAT-2005)/9th International Conference on Advanced Materials (ICAM 2005), Singapore, SINGAPORE, 2005.

7 T. Ioroi, H. Senoh, S. Yamazaki, Z. Siroma, N. Naoko Fujiwara and K. Yasuda, Journal of The Electrochemical Society, 2008, 155, B321-B326.

8 K. Tammeveski, T. Tenno, A. Rosental, P. Talonen, L. S. Johansson and L. Niinisto, J. Elecrochem. Soc., 1999, 146, 669-676.

9 K. Tammeveski, M. Arulepp, T. Tenno, C. Ferrater and J. Claret, Baltic Conference on Interfacial Electrochemistry - Electrochemical Reactivity of Electrode Surface, Tartu, Estonia, 1996.

10 L. M. Vračar, N. V. Krstajić, V. R. Radmilović and M. M. Jakśić, J. Electroanal. Chem., 2006, 587, 99-107.

11 S. Guerin and B. E. Hayden, J.Comb.Chem., 2006, 8, 66-73.

12 S. Guerin, B. E. Hayden, D. Pletcher, M. E. Rendall, J. P. Suchsland and L. J. Williams, J.Comb.Chem., 2006, 8, 791-798.

13 S. Guerin, B. E. Hayden, D. Pletcher, M. E. Rendall and J. P. Suchsland, J.Comb.Chem., 2006, 8, 679-686.

14 B. E. Hayden, D. Pletcher and J.-P. Suchsland, Angewandte Chemie Int. Ed., 2007, 46, 3530-3532.

15 B. E. Hayden, D. Pletcher, M. E. Rendall and J.-P. Suchsland, J.Phys.Chem.C., 2007, 111, 17044-17051.

16 W. Vielstich, H. A. Gasteiger and A. Lamm eds., Handbook of Fuel Cells, Wiley, 2003.

17 D. Pletcher and F. C. Walsh, Industrial Electrochemistry, Chapman and Hall, 1990.

18 B. E. Hayden, D. Pletcher, J. P. Suchsland and L. J. Williams, Phys.Chem.Chem.Phys., 2009, 11, 1564-1570.

19 K. J. J. Mayrhofer, B. B. Blizanac, M. Arenz, V. R. Stamenkovic, P. N. Ross and N. M. Markovic, J.Phys.Chem.B., 2005, 109, 14433-14440.

20 K. Kinoshita, John Wiley \& Sons, 1992.

21 P. Stonehart, in Electrochemistry and Clean Energy, ed. J. A. G. Drake, The Royal Society of Chemistry, Cambridge, 1994.

22 F. Maillard, E. R. Savinova and U. Stimming, J. Electroanal. Chem., 2007, 599, 221-232.

23 J. Solla-Gullon, F. J. Vidal-Iglesias, E. Herrero, J. M. Feliu and A. Aldaz, Electrochemistry Communications, 2006, 8, 189-194. 
24 K. Kinoshita, J. Electrochem. Soc., 1990, 137, 845-848.

25 S. Guerin, B. E. Hayden, C. E. Lee, C. Mormiche, J. R. Owen, A. E. Russell, B. Theobald and D. Thompsett, J.Comb.Chem., 2004, 6, 149-158.

26 A. Gamez, D. Richard, P. Gallezot, F. Gloaguen, R. Faure and R. Durand, Electrochimica Acta, 1996, 41, 307-314.

27 Y. Takasu, N. Ohashi, X. G. Zhang, Y. Murakami, H. Minagawa, S. Sato and K. Yahikozawa, Electrochimica Acta, 1996, 41, 2595-2600.

28 M. Watanabe, H. Sei and P. Stonehart, J. Electroanal. Chem., 1989, 261, 375-387.

29 H. Yano, J. Inukai, H. Uchida, M. Watanabe, P. K. Babu, T. Kobayashi, J. H. Chung, E. Oldfield and A. Wieckowski, Phys. Chem. Chem. Phys., 2006, 8, 49324939.

30 S. Mukerjee and J. McBreen, J. Electroanal. Chem., 1998, 448, 163-171.

31 B. E. Conway, Progress in Surface Science, 1995, 49, 331-452.

32 B. E. Hayden, D. V. Malevich and D. Pletcher, Electrochem.Comm., 2001, 3, 395399.

33 H. Pelouchova, P. Janda, J. Weber and L. Kavan, J. Electroanal. Chem., 2004, 566, 73-83.

34 F. Maillard, S. Schreier, M. Hanzlik, E. R. Savinova, S. Weinkauf and U. Stimming, Phys. Chem. Chem. Phys., 2005, 7, 385-393. 


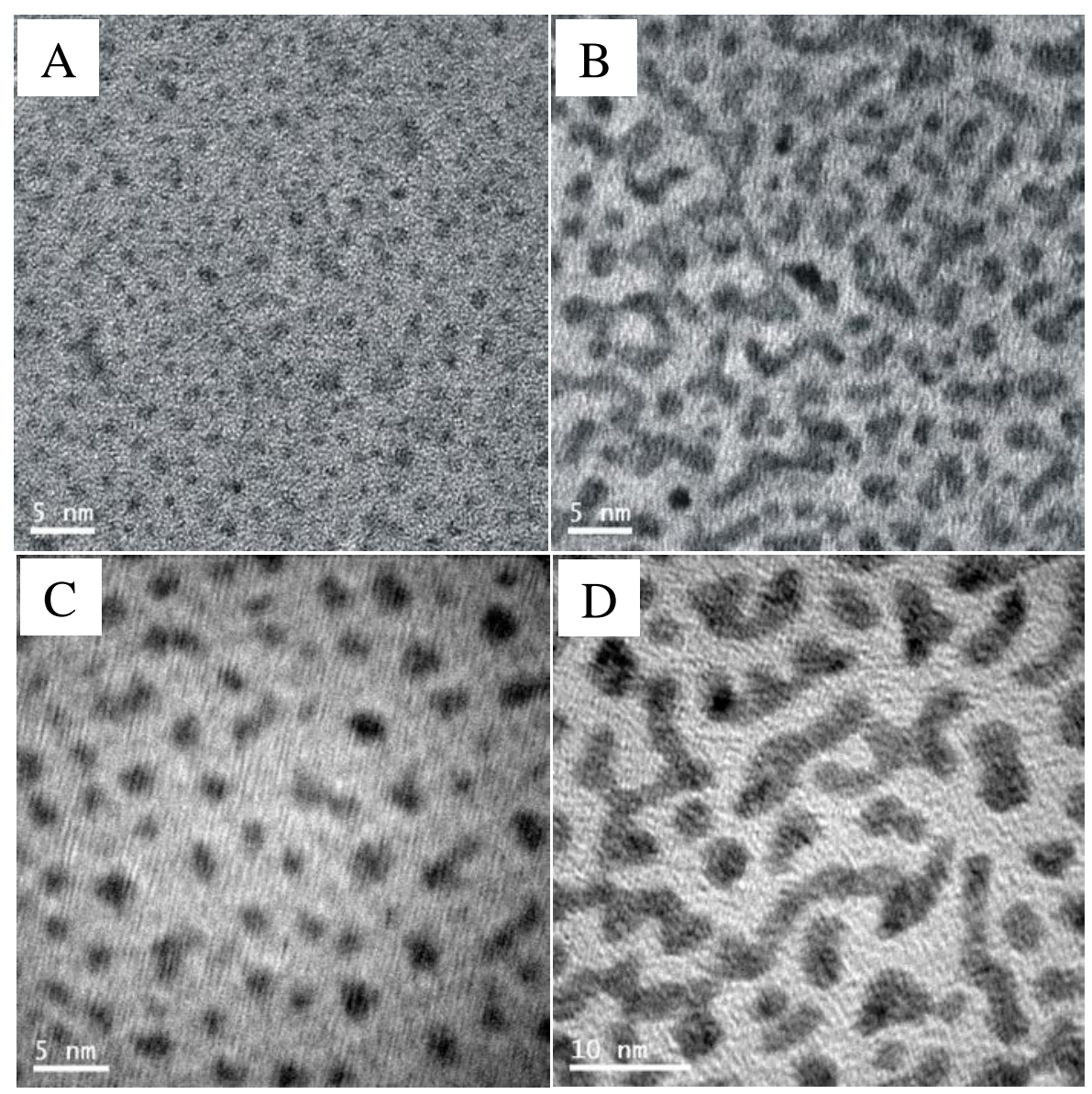

Figure 1 TEM images of $\mathrm{TiO}_{\mathrm{x}}(\mathrm{A}, \mathrm{B})$ and carbon (C, D) supported platinum surfaces with Pt equivalent thicknesses of $0.2 \mathrm{~nm}$ and $0.6 \mathrm{~nm}$ respectively. 


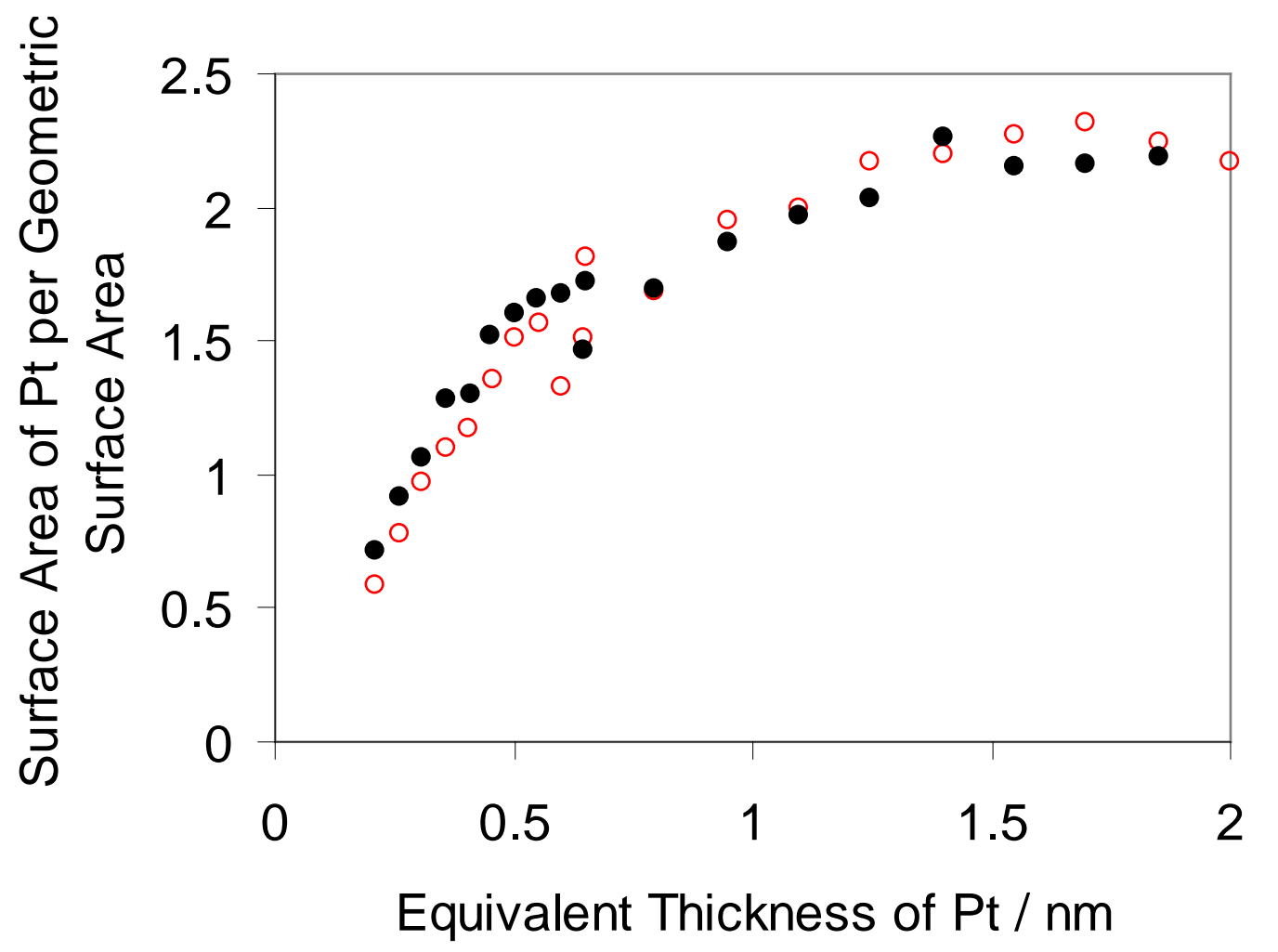

Figure 2 The surface area of Pt exposed to electrolyte as a function of the equivalent thickness of $\mathrm{Pt}$ in the carbon (filled circles) and $\mathrm{TiO}_{\mathrm{x}}$ (open circles) supported platinum surfaces. The surface areas are estimated from the charge under the hydrogen adsorption peaks on cyclic voltammograms in $0.5 \mathrm{M} \mathrm{HClO}_{4}$. 

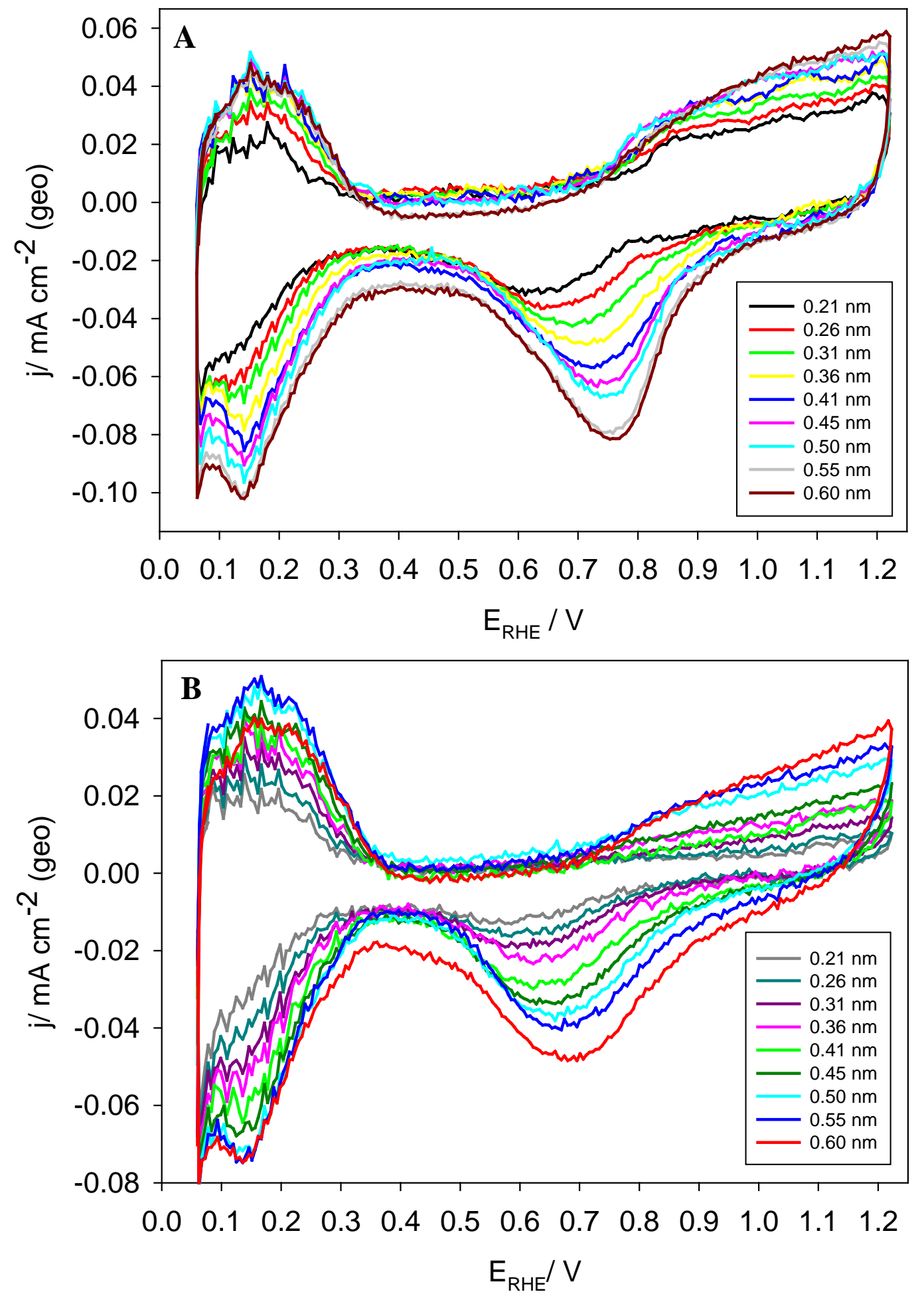

Figure 3 Cyclic voltammograms of catalysts on carbon (A) and $\mathrm{TiO}_{\mathrm{x}}(\mathrm{B})$ at various equivalent thicknesses (given in the inset) of platinum. The voltammetry was carried out in $0.5 \mathrm{M} \mathrm{HClO}_{4}$ electrolyte at $298 \mathrm{~K}$, and at a scan rate $50 \mathrm{mV} \mathrm{s}^{-1}$. 


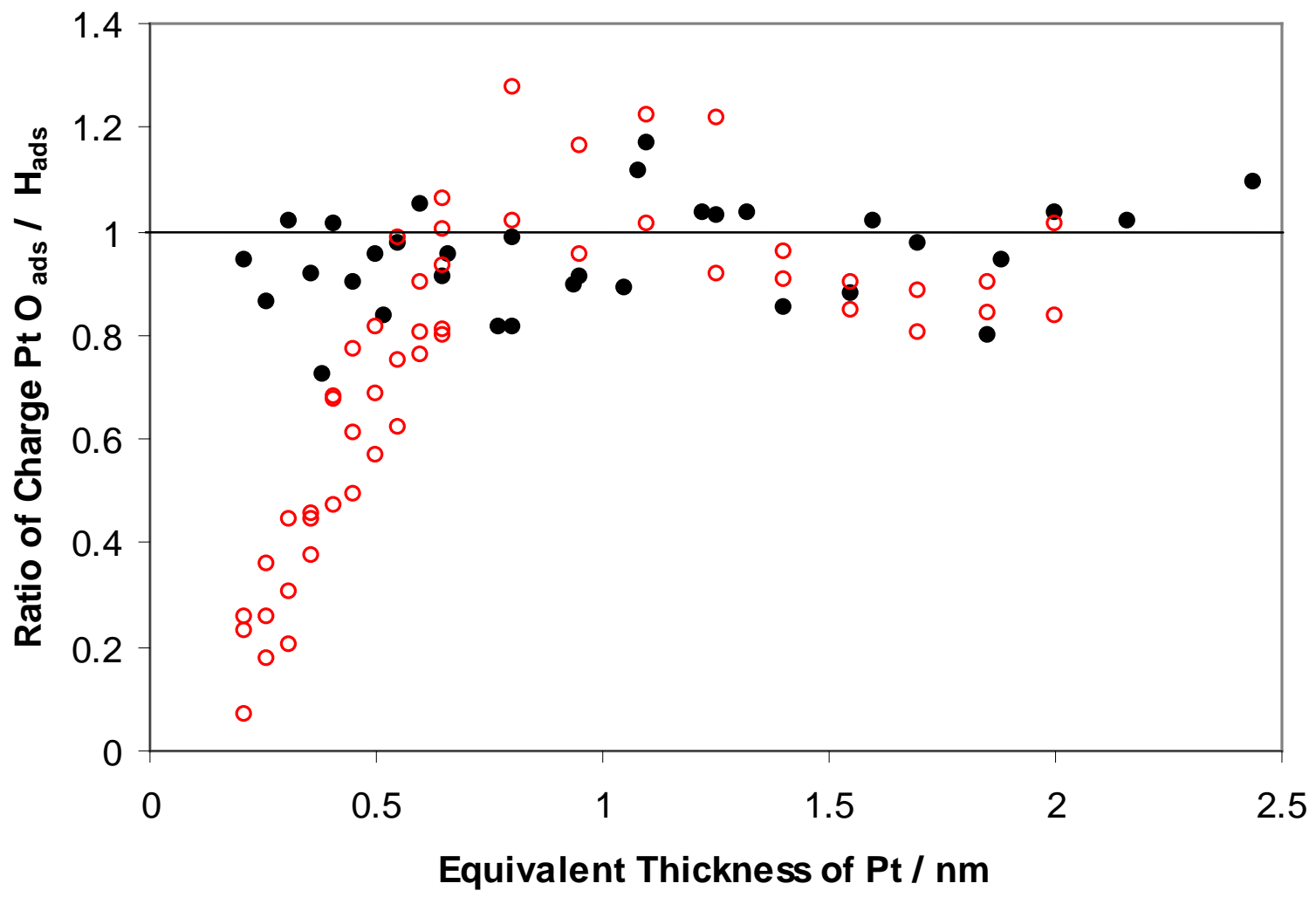

Figure 4 The ratio of charge under the platinum oxide reduction peak to that under the hydrogen adsorption peaks as a function of the equivalent thickness of platinum on carbon (filled circles) and $\mathrm{TiO}_{\mathrm{x}}$ (circles). The voltammetry was carried out in Ar purged $0.5 \mathrm{M} \mathrm{HClO}_{4}$ electrolyte at $298 \mathrm{~K}$, and at a scan rate $50 \mathrm{mV} \mathrm{s}^{-1}$. 

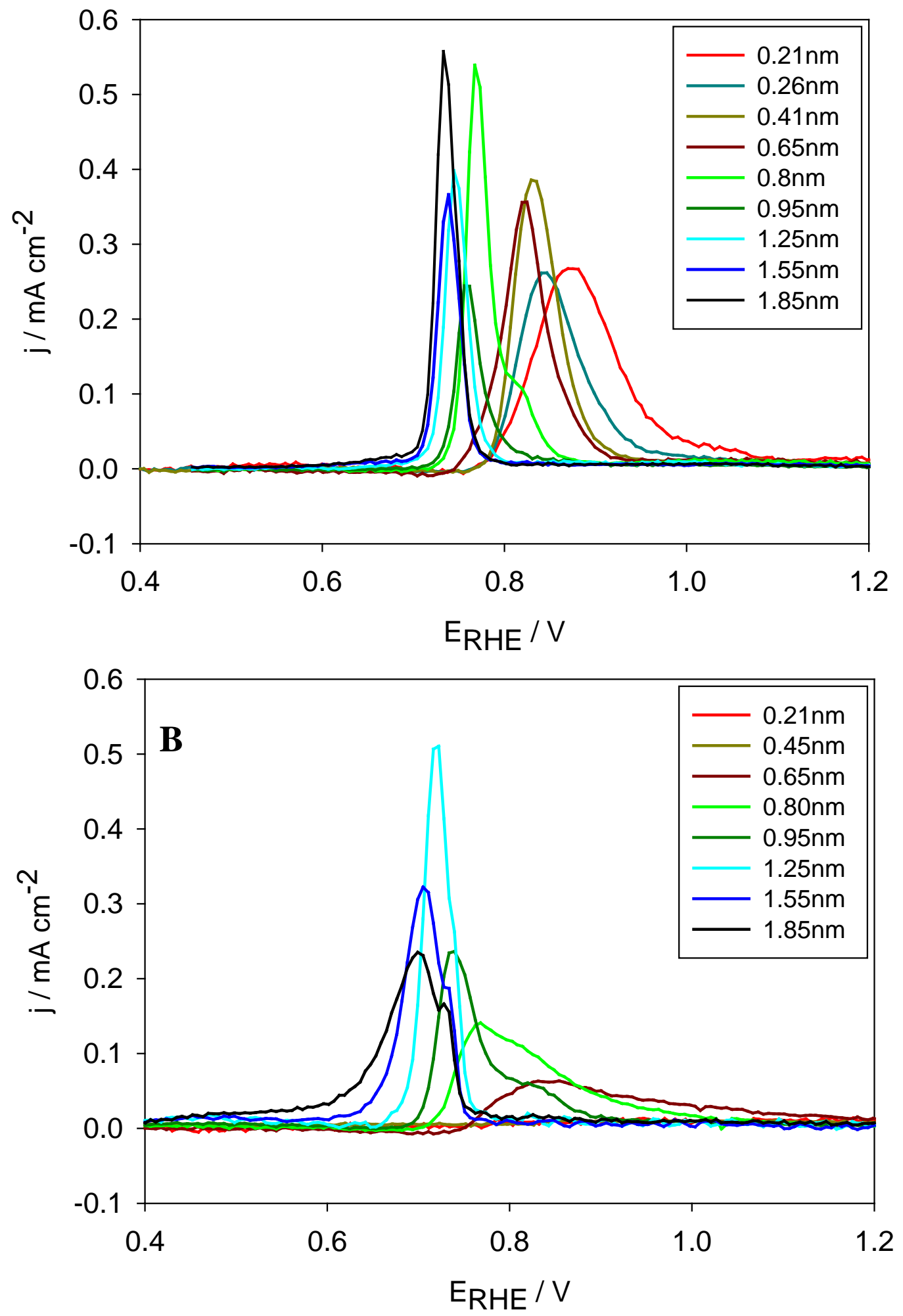

Figure 5 CO stripping peaks from carbon (A) and $\mathrm{TiO}_{\mathrm{x}}$ (B) supported platinum electrodes. The current on the second cycle has been subtracted from the first cycle. The equivalent Pt loadings are given in the inset. The voltammetry was carried out in $0.5 \mathrm{M} \mathrm{HClO}_{4}$ electrolyte at $298 \mathrm{~K}$, and at a scan rate $50 \mathrm{mV} \mathrm{s}^{-1}$. 


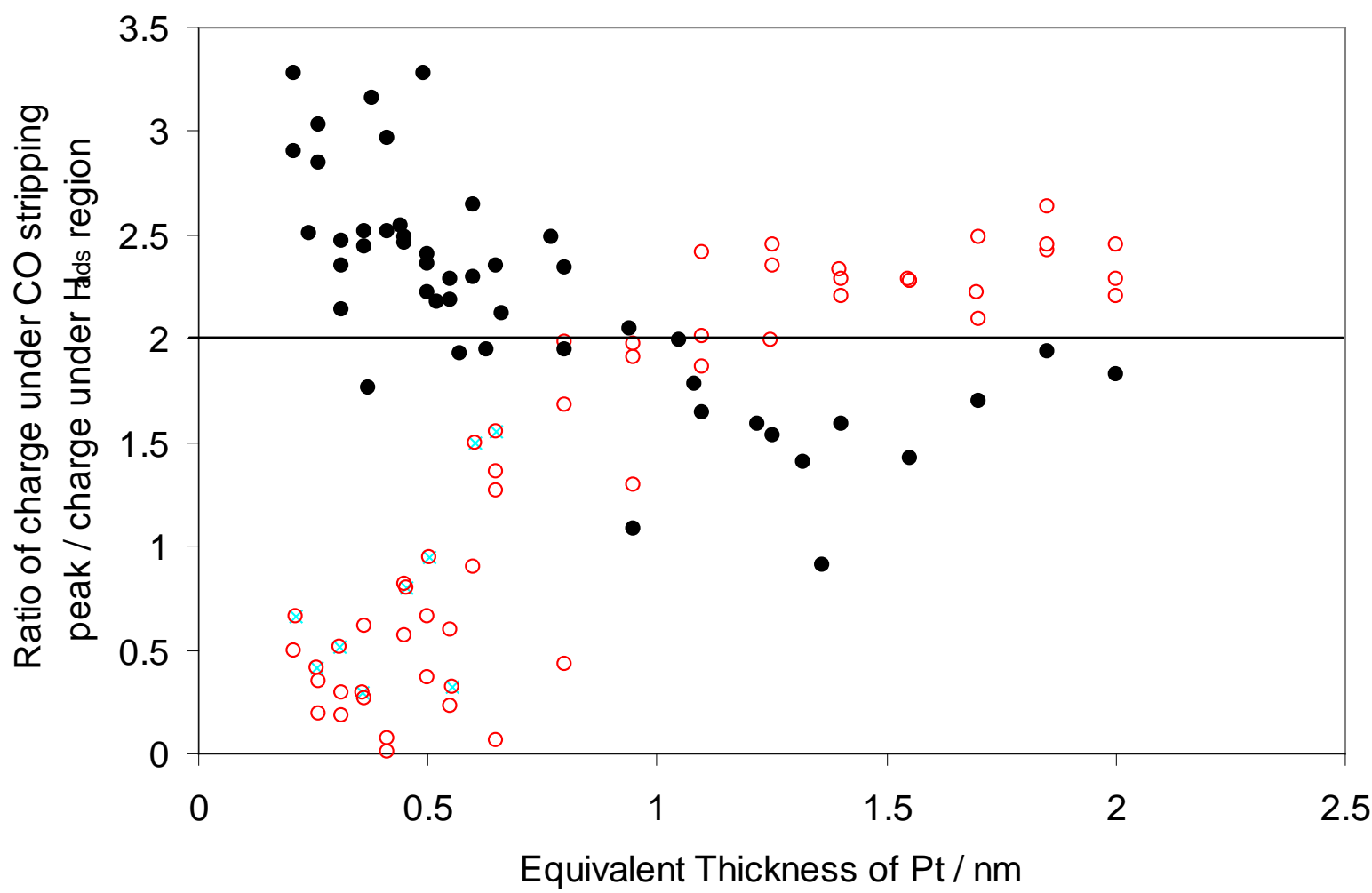

Figure 6 The ratio of charge under the CO stripping peak to the charge for hydrogen adsorption as a function of the equivalent thickness of platinum on $\mathrm{TiO}_{\mathrm{x}}$ (circle) and carbon (filled circle). 

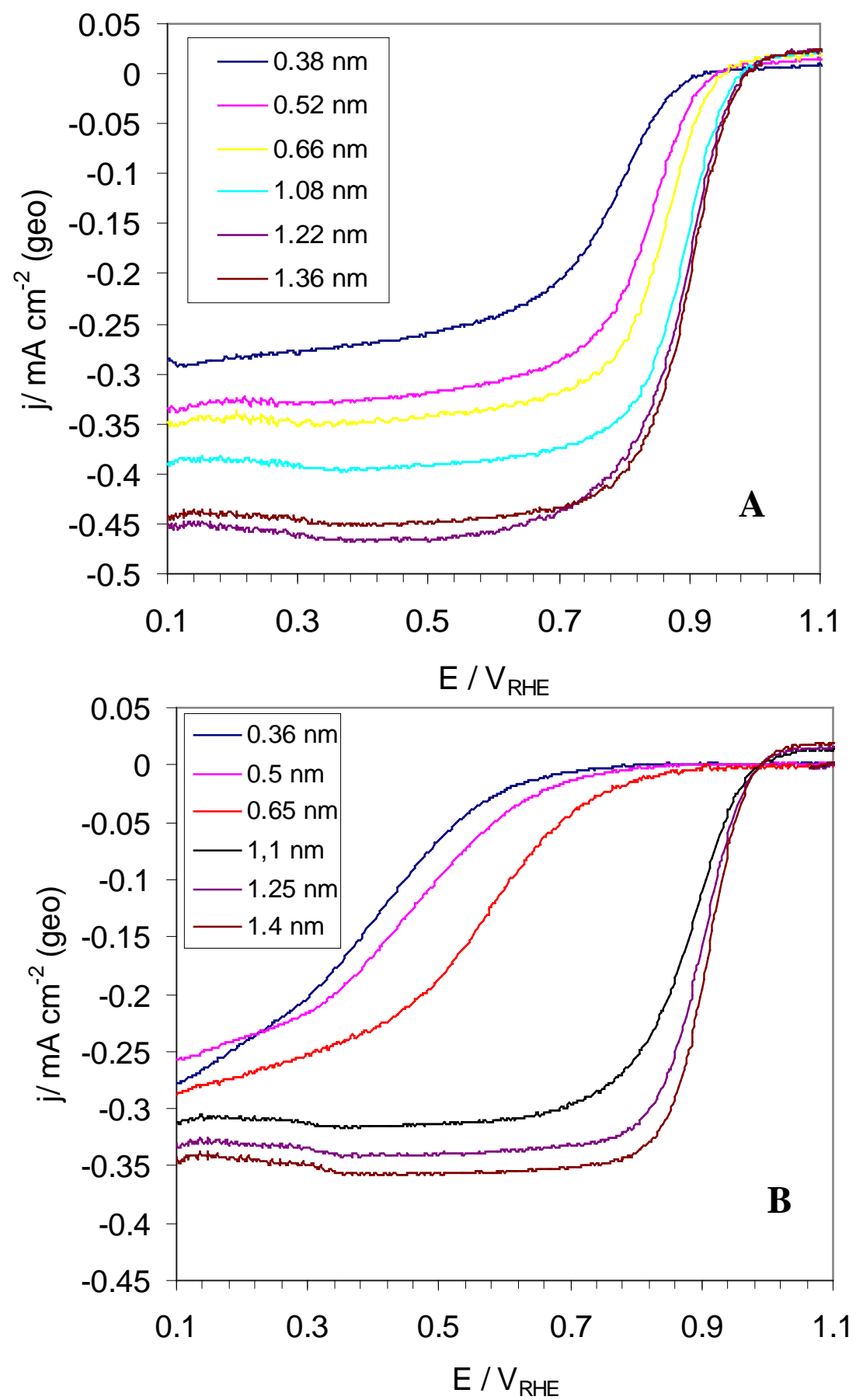

Figure 7 Oxygen reduction on carbon (A) and $\mathrm{TiOx}(\mathrm{B})$ supported platinum electrodes. Averaged cyclic voltammograms are shown measured in $\mathrm{O}_{2}$ saturated $0.5 \mathrm{M} \mathrm{HClO}_{4}$ electrolyte at $25{ }^{\circ} \mathrm{C}$ at $20 \mathrm{mV} \mathrm{s}^{-1}$. 


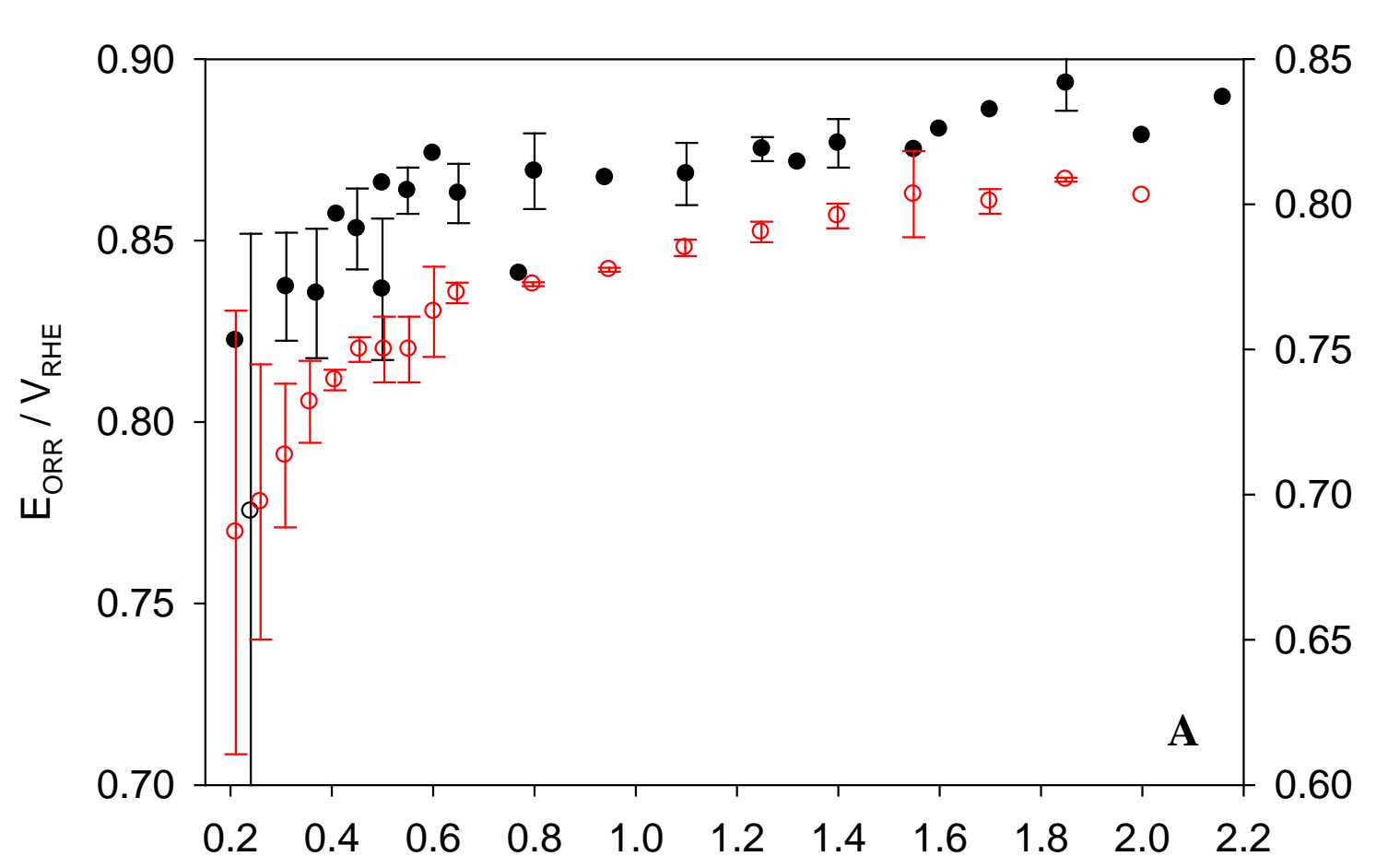

Equivalent Thickness of $\mathrm{Pt} / \mathrm{nm}$

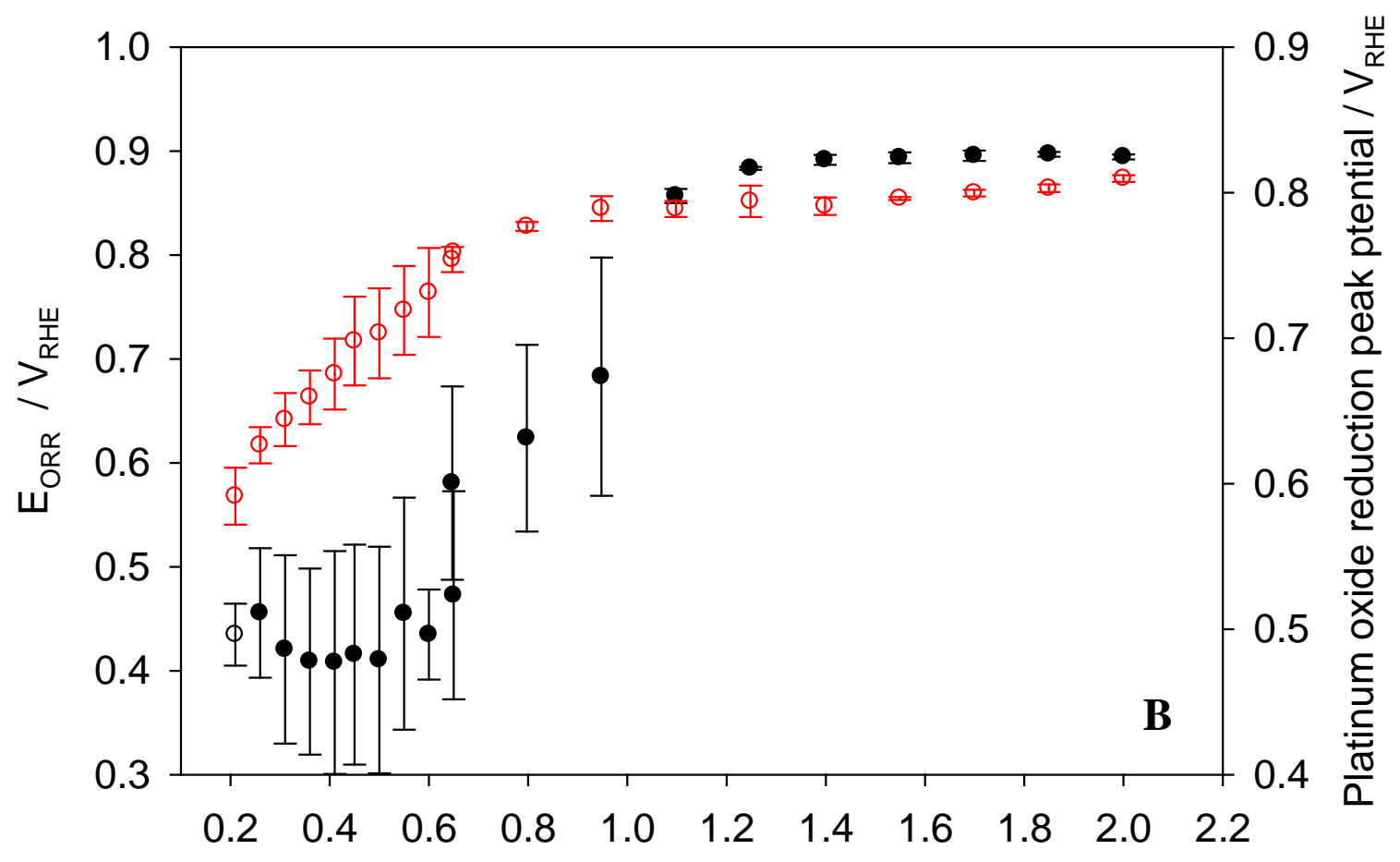

Equivalent Thickness of $\mathrm{Pt} / \mathrm{nm}$

Figure 8 The $\mathrm{E}_{\mathrm{ORR}}$ (The potential at which $0.01 \mathrm{~mA} \mathrm{~cm}^{-2}$ (real $\mathrm{H}_{\mathrm{ads}}$ ) is reached during oxygen reduction) (filled circles) and the platinum oxide reduction peak potential $\left(E_{S R}\right)$ (open circles) as a function of the effective thickness of platinum supported on carbon $(\mathrm{A})$ and $\mathrm{TiO}_{\mathrm{x}}(\mathrm{B})$. 


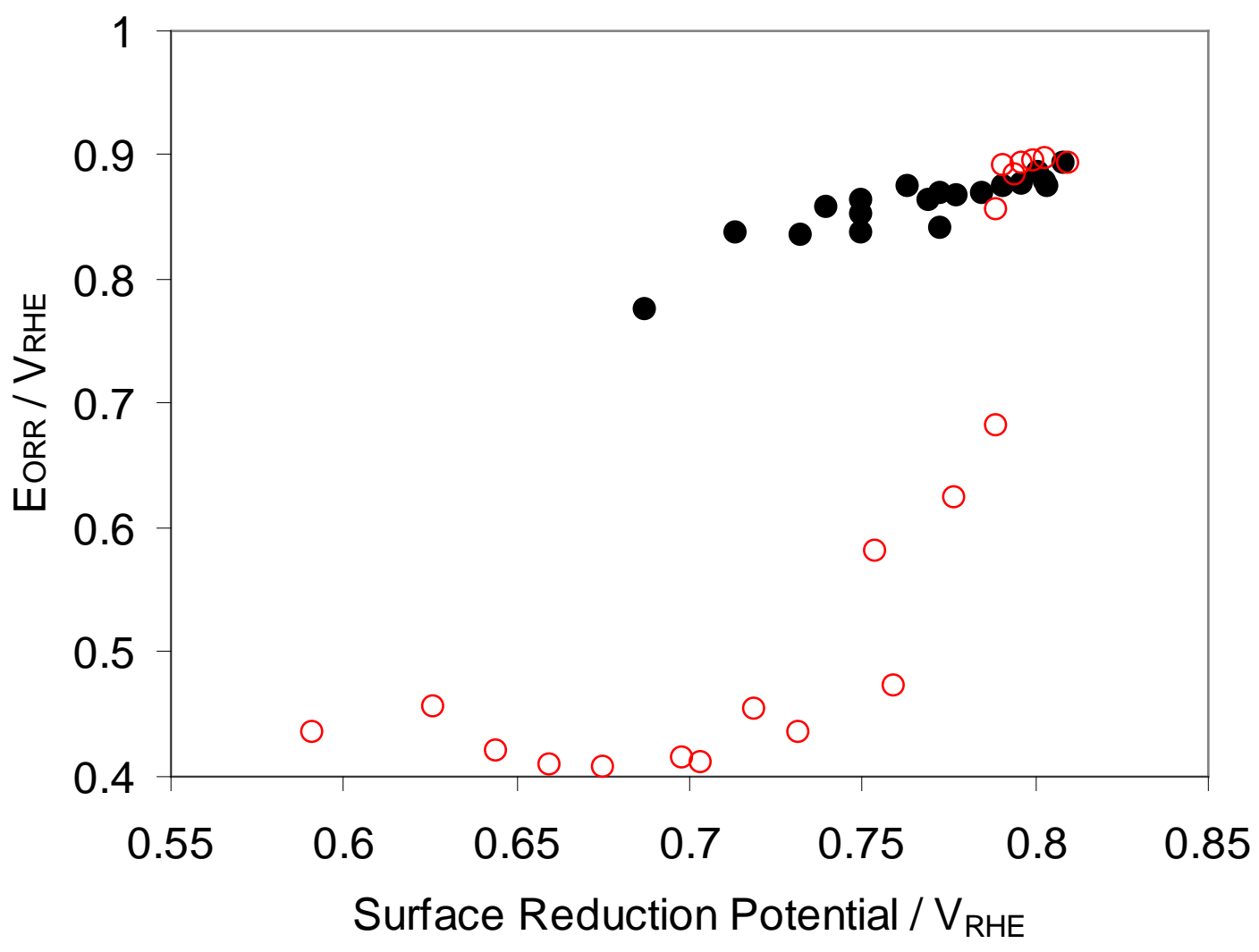

Figure 9 The $\mathrm{E}_{\mathrm{ORR}}$ (The potential at which $0.01 \mathrm{~mA} \mathrm{~cm}^{-2}$ (real $\mathrm{H}_{\mathrm{ads}}$ ) is reached during oxygen reduction) as a function of the platinum oxide reduction peak potential $\left(\mathrm{E}_{\mathrm{SR}}\right)$ for platinum supported on carbon (filled circles) and $\mathrm{TiO}_{\mathrm{x}}$ (open circles). 